\title{
Principles of Information Integration of the Mono-profile Situational Centers for Effective Disaster Management
}

\author{
Sergey A. Mescherin ${ }^{1}$, Igor A. Kirillov ${ }^{2}$, Stanislav V. Klimenko ${ }^{3}$ \\ ${ }^{1}$ Moscow Institute of Physics and Technology, sergey.metcherin@gmail.com \\ ${ }^{2}$ Institute of Computing for Physics and Technology, \\ kirillov.igor@gmail.com \\ ${ }^{3}$ Institute of Computing for Physics and Technology, stanislav.klimenko@gmail.com
}

\begin{abstract}
Article is focused on a problem of information integration of the mono-profile situational centers for increasing of the overall disaster management efficiency. Calamity $9 / 11$ case is used as a demonstration of unacceptable consequences due to absence of information integration. Special role of Common Operational Picture is demonstrated for provision of the effective disaster management decisions. It is proposed to use a Shared Situational Awareness as a one of key performance indicators for development and maintenance of united disaster management "system-of-systems" for Moscow megalopolis. Four basic principles, which can form foundation of integrated disaster management system of Moscow, are described
\end{abstract}

Keywords: disaster management, common operation picture, resilience, systemof-systems, information integration, mono-profile situational centers, riskinformed

\section{Introduction}

In recent decades intensity and frequency of the man-made accidents and natural catastrophes are permanently growing. For restriction of the calamity scale and/or mitigation of the unacceptable consequences, the enormous resources are required and the multiple different systems (federal agencies and municipal organizations - Ministry of Emergency, ambulance, police, fire brigades, etc.) are involved. Each of disastermanagement-dedicated system has its own tasks, resources and responsibilities.

In case of any severe accident, a problem of effective management of the multiple heterogeneous systems appeared. Pivotal questions are - how to provide 1) effective interaction of the different municipal services, and collaboration of the federal and urban organizations, 2) justin-time, accurate and targeted information on current situation, 3) rational allocation of the resources?

Detailed analysis of current state-ofaffairs in Moscow shows, that now the different federal agencies and municipal organizations have their own Situational Centers (SC) inside of Moscow megalopolis - for example, in Ministry of Emergency of RF, in Ministry of Natural Resources of RF, in State Corporation RosAtom, etc.. These mono-profile (or mono-disciplinary) SCs are acting in their own interests in first turn [1]. On belief of the mono-profile SCs owners, the most important results of launching of the Situational Centers are improvements in 
quality of decision making and reducing of the reaction time for the revealed threats or hazards.

However, collection even multiple mono-profile SCs with weak interaction and collaboration is unable, in principle, to provide comprehensive, integrated and effective disaster management. It is especially true in case of large-scale severe accidents or catastrophes. Requested level of safety and security can be obtained via information integration of the different mono-profile Situational Centers, belonging now for different agencies and organizations. In fact, it is a matter of formation of "system-of-systems" (SoS), where each separate mono-profile SC is a "sub-system", which interact with the other "sub-system" according to the unified operational protocols and data formats.

Necessity in, at least, information integration for effective disaster management is under discussion for a long time in professional communities [2] in Russia. Topical nature of mentioned problem at governmental level is fixed in item 107 of National Security Strategy of Russian Federation [3].

In this article, the problem of information integration of the mono-profile situational centers i Moscow megalopolis into unified (network-enabled) system ("system-of-systems") is considered from viewpoint of methodology of integration. Main goal of current work is to answer on what methodological principles it will be worthwhile to integrate the different mono-profile situational centers ? For development and maintenance of a really comprehensive and dynamic disaster management SoS, four keystone principles are proposed.

In Section 2, the calamity $9 / 11$ case is used as a demonstration of unacceptable consequences due to absence of information integration. Special role of Common Operational Picture (COP) is demonstrated for provision of the effective disaster management decisions. It is proposed to use a Shared Situational Awareness (SSA) as a one of key performance indicators for development and maintenance of united disaster management "system-of-systems" for Moscow megalopolis. In Section 3 four basic principles, which can form foundation of integrated disaster management system of Moscow, are described. Section 4 summarizes the conclusions of our study

\section{Shared Situation Awareness as a prerequisite and performance indi- cator for effective decision making}

Absence of a direct and reliable information channel between New York Police Department and Fire Brigades at downstream level (between the pilots of police helicopters and the fire-fighters inside of building) during 9/11 calamity at World Trade Center in New York results in groundless deaths of the firefighters during building collapse [4]. Information on threat of building collapse was distributed along police radio channel to all policemen at 21 minute ahead of collapse. Critically important information was not transmitted to fire-fighters due to inconsistency of the police and the fire brigades radio channels and operational procedures. Eventually, the 121 firefighters were cutted-off from vital information and perished.

Absence, incompleteness or ill-timed formation of Shared Situational Awareness (shared between disaster stakeholders) is one of the main factor, which results unacceptable losses (in man-made accidents in off-shore and chemical industries [5], in aviation [6], in military operations [7].

In summary, inevitability of interagency and inter-organizational information integration is defined by direct danger of unjustifiable losses in case of usage of a 
mono-profile approach during and before severe accident. Shared Situation Awareness is absolutely necessary for generation of right decision under severe accident conditions and, consequently, for successful implementation of mitigation and rescue operations.

In united disaster management "System-of-systems", the Shared Situation Awareness is, from one side - one of the main governing parameter, which influence on decision making, and, on the other hand, it can be used as 1) performance indicator for development of SoS and 2) as maturity criterion for currently available mono-profile Situational Centers (sub-systems) form viewpoint of efficiency of their interaction (information exchange and cooperation within framework of the obtained command, synchronization of actions, etc.).

\section{Four Basic Principles of Infor- mation Integration for Effective Disaster Management from Resili- ence Perspective}

Electronic and procedural integration of the information systems of the different disaster management stakeholders (federal agencies, municipal organizations) can be organized using different frameworks. Here, we delineate two aspects of integration - 1) for what goal integration will be made (SoS's objective function viewpoint)?, 2) on what kind of information semantics an integration will be made (SSA model viewpoint)?

In contrast to the risk-informed frameworks, which are dominating now [8][13], thereafter in this paper we will discuss problem of information integration from viewpoint of an innovative resilience-based paradigm for built environment [14]. From SSA model viewpoint, our treatment will based on works of Endsley and their co-workers [15], where three basic levels of SSA are considered: level 1 - comprehension of environment in unified space-time representation, level 2 - awareness of the elements and links, level 3 - projection of the state into nearest future.

\subsection{Principle 1. Network-enabled Sit- uation Awareness Sharing}

For sharing of a unified Situation Awareness across a whole "System-of Systems" it will be reasonable to use the all capabilities of the wide-band, high-throughput electronic networks, including wireless ones. Sharing shall be made, at least, over three channels, which correspond to three basic level of Situation Awareness in Endsley model [15].

\subsection{Principle 2. Multi-Scale Monitor- ing of Pre-cursors and Misshapes}

In order to provide information interaction of the different sub-systems at level 1 of Endsley's model (comprehension of environment), the primary data (measurable or computed), which characterize the assets-at-risk, shall be represented in multi-scale view. This multi-scale view shall provide collection/storage/use/reuse of the accident scene, hazards/threats and assets-at-risk.

\subsection{Principle 3. Model-based Assess- ment of Performance/State-of- Health of System-at-Risk and Threats/Hazards}

In order to provide information exchange between the different sub-systems at level 2 of Endsley's model, in SoS should be the unified tools and appropriate infrastructure for quantitative description of the threats/hazards and performance of the System-at-Risk and its State-ofHealth [16]. Performance indexes can be obtained either from processing of the primary data from sensors or derives on the base of simulations by computational 
models, reproducing behavior of real objects (threat carriers or asset at-risk) [17].

\subsection{Principle 4. Risk-informed Deci- sion Support}

In order to provide information interaction of the different sub-systems at level 3 of Endsley's model, the Sos under development shall be capable to support riskinformed decision making [17]. Risk assessment, performed on the base of permanent monitoring of threat/hazards, is used for searching of the vulnerable or "weak" points in system-at-risk. Maps of risks is used for development of the countermeasures, targeted on vulnerabilities with highest rank.

\section{Conclusions}

1. Methodological problem of information integration of the mono-profile federal and municipal

situational centers for effective disaster management in Moscow megalopolis.

2. Calamity $9 / 11$ case was used as a demonstration of unacceptable consequences due to

absence of information integration. Special role of Common Operational Picture (COP) is demonstrated for provision of the effective disaster management decisions.

3. It is proposed to use a Shared Situational Awareness (SSA) as a one of key performance indicators for development and maintenance of united disaster management "system-of-systems" (SoS) for Moscow megalopolis.

4. On the base paradigm for resilience of built environment and Endsley's model for Shared Situation Awareness, the four basic principles, which can form foundation of integrated disaster management system of Moscow, are described.

5. Integration of the existing monoprofile Situational Centers in Moscow it will be reasonable to perform using stage approach. At first stage to provide network-enabled framework (Principle 1 and 2 ). At second stage to introduce modelbased capabilities (Principle 3). At third stage to provide compliance with riskinformed decision making (Principle 4).

\section{Acknowledgement}

Authors are grateful to the Russian Foundation of Basic Research for support of the grants, targeted on the development of the risk-informed technologies (11-0700329-a) and advanced visualization systems (11-07-13166-ofi-M-2011_RZD) for crisis management.

\section{References}

[1] "Situational Centers" Conference, http://www.scconf.ru/ru/content/categ ory/8/23/51/ (in Russian).

[2] interview of S.K. Shoigu (Head of Ministry of Emergency RF), "Integrated Safety and Security - 2009" Conference, (ISSE-2009),

http://www.cnews.ru/reviews/free/go v2009/articles/sc_gosupr.shtml (in Russian)

[3] Strategy of National Safety and Security of Russian Federation until 2020. In: Decree of President of RF, \#537, 2009 (in Russian)

[4] Dwyer, K. Flynn and F. Fessenden, Why police made it out of the World Trade Center when firefighters didn't, The New York Times, http://www.scanboston.com/fdny911 problems $2 . h$ tm

[5] R. Flin and P. O'Connor, "Applying crew resource management in offshore oil platforms", In E. Salas, C.A. Bowers, \& E. Edens (Eds.), Improving teamwork in organization: Applications of resource management training (pp. 217-233). Hillsdale, NJ: Erlbaum, 2001. 
[6] R. T. Nullmeyer, D. Stella, G. A. Montijo and S. W. Harden, "Human factors in Air Force flight mishaps: Implications for change". Proceedings of the 27th Annual Interservice/Industry Training, Simulation, and Education Conference (paper no. 2260). Arlington, VA: National Training Systems Association, 2005

[7] J. C. Gorman, N. J. Cooke and J. L. Winner, "Measuring team situation awareness in decentralized command and control environments", Ergonomics, v.49, no. 12-13, pp.1312-1325, 2006

[8] M. L. Markus, J. Fedorowicz, D. Bodeau, D., J. Brooks, Characterizing and Improving Collaboration and Information-Sharing Across Emergency Preparedness and Response Communities

[9] Kebair, F., Serin, F.: Agent-based Decision Support System to Prevent and Manage Risk Situations. In: 16ème Congrès de Maîtrise des Risques et de Sûreté de Fonctionnement, 2008

[10] S. H. Othman, G. A. Beydoun, A Disaster Management Metamodel (DMM) Validated Knowledge Management and Acquisition for Smart Systems and Services, Lecture Notes in Computer Science, Volume 6232/2010, 111-125, DOI: 10.1007/978-3-642-15037-1_11, 2010

[11] F. Benaben, C. Hanachi, M. Lauras, P. Couget, V. Chapurlat, A Metamodel and its Ontology to Guide Crisis Characterization and its Collaborative Management. In: Proceedings of the $5^{\text {th }}$ International ISCRAM Conference - Washington, DC, USA, pp.189- 196, 2008

[12] Gang Kou, Chunwei Lou, Guoxun Wang, Yi Peng, Yu Tang,
Shiming Li, "A heterogeneous information integration framework for emergency management", in Information Sciences and Interaction Sciences (ICIS), 2010 3rd International Conference on, 23-25 June, pp. 672 675, 2010

[13] Van Rijk, Post, van Verseveld, O.H., "Crisiskit: Development and evaluation of a program on team processes in crisis management", Rep. No. TNO-TM-01-D016, TNO Defense, Safety and Security, 2001

[14] I. A. Kirillov, S. V. Klimenko, Plato's Atlantis Revisited: Riskinformed, Multi-Hazard Resilience of Built Environment via Cyber Worlds Sharing. In: 2010 International Conference on Cyberworlds (CW), 20-22 Oct. 2010 Singapore, 10.1109/CW.2010.38, pp.445-450, 2010

[15] M. R. Endsley, Theoretical underpinnings of situation awareness: A critical review. In: M.R. Endsley \& D.J. Garland (Eds.), Situation awareness analysis and measurement. Mahwah, NJ, LEA, 2000

[16] I. A. Kirillov, S. A. Metcherin, S. V. Klimenko, Metamodel of Shared Situtation Awareness for Resilience Management of Built Environment, Intern. Conf. on CyberWorlds2012, 23-25 September, Darmstadt, pp.137143,2012

[17] J. Trnka, B. Johansson (2009). Collaborative command and control practice: Adaptation, selfregulation and supporting behavior. Int. J. Information Systems for Crisis Response and Management, 1(2), 47-67

[18] Risk-informed decision making, NRC, 2007, http://www.nrc.gov/readingrm/basicref/glossary/risk-informeddecisionmaking.html 